\title{
Effects of salinity and particle concentration on sediment hydrodynamics and critical bed-shear-stress for erosion of fine grained sediments used in wetland restoration projects
}

\author{
MALAY GHOSE-HAJRA, ALEX McCORQUODALE, GREGORY MATTSON, \\ DONALD JEROLLEMAN \& JOHN FILOSTRAT
}

The University of New Orleans, New Orleans, Louisiana, USA

mghoseha@uno.edu

\begin{abstract}
Sea-level rise, the increasing number and intensity of storms, oil and groundwater extraction, and coastal land subsidence are putting people and property at risk along Louisiana's coast, with major implications for human safety and economic health of coastal areas. A major goal towards re-establishing a healthy and sustainable coastal ecosystem has been to rebuild Louisiana's disappearing wetlands with fine grained sediments that are dredged or diverted from nearby rivers, channels and lakes to build land in open water areas. A thorough geo-hydrodynamic characterization of the deposited sediments is important in the correct design and a more realistic outcome assessment of the long-term performance measures for ongoing coastal restoration projects. This paper evaluates the effects of salinity and solid particle concentration on the re-suspension characteristics of fine-grained dredged sediments obtained from multiple geographic locations along the Gulf coast. The critical bed-shear-stress for erosion has been evaluated as a function of sedimentation time. The sediment hydrodynamic properties obtained from the laboratory testing were used in a numerical coastal sediment distribution model to aid in evaluating sediment diversions from the Mississippi River into Breton Sound and Barataria Bay.
\end{abstract}

Key words erosion; restoration; sediment; shear stress; salinity; grain size distribution; re-suspension, sedimentation.

\section{INTRODUCTION}

Sea level rise, the increasing number and intensity of coastal storms, and other natural and human hazards are putting more people and property at risk in Louisiana, with major implications for human safety and the economic health of coastal areas. The state of the Louisiana coast has been declining steadily since the 1930s. As of 2012, an estimated 1880 square miles (486 917 ha) of Louisiana coastal land has been lost (2012 Louisiana Coastal Master Plan: CPRA, 2012). The last 20 years has seen an increased rate of land loss that will continue to worsen if no action is taken. Figure 1 indicates the land change scenario for the next 50 years if no action is taken to conserve and protect future land loss as well as create new land. The areas marked in red will be lost or inundated if no action is taken to save coastal Louisiana.

As evident from Fig. 1, a significant portion of these areas lies within the Lake Pontchartrain Basin. It is therefore important that efforts are made to minimize the land loss process, and possibly reverse the cycle, by building new land.

\section{USE OF DREDGED SEDIMENTS IN LAND CREATION}

Over the last several years, various techniques have been employed to restore the fragile wetlands of Louisiana. As indicated in the Louisiana Coastal Master plan, one of the major goals towards re-establishing a healthy hydro-geomorphic ecosystem is to rebuild wetlands with river/canal/lake sediment diversion or sediment conveyance projects that optimally manage and allocate sediments. This dredged material, previously mostly wasted, can now be used to build new land in coastal Louisiana. Native or recently deposited in situ material can also be mechanically or hydraulically dredged from its location in a fresh, brackish, or saltwater environment and transported in pipelines and distributed in open water areas for land creation and marsh re-nourishment.

\section{GEOTECHNICAL CHARACTERIZATION OF SEDIMENTS}

The engineering properties and material characteristics of the dredged material are input parameters in most computational models used to predict the long-term behaviour of sediments in the environment (Star et al., 2005). Therefore, proper geotechnical characterization of the dredged 


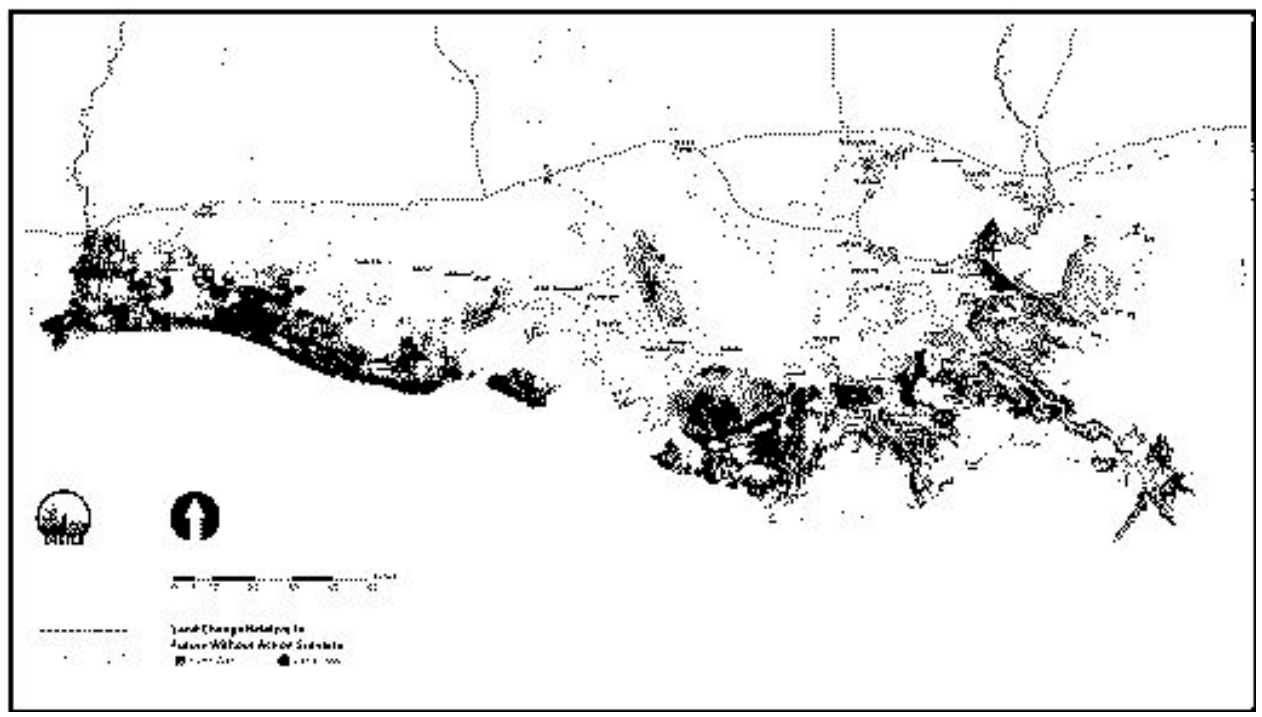

Fig. 1 Land change relative to future without action (2012 Louisiana Coastal Master plan).

material is of utmost importance in the correct design of coastal restoration and land reclamation projects. The sedimentation and re-suspension characteristics of the dredged material as well as their effects on the time rate of settlement of the suspended solid particles and underlying foundation soil depend, among other factors, on (a) the grain size distribution of the dredged material, (b) salinity (fresh, brackish, or saltwater environment) of the composite slurry, and (c) the concentration of the solid particles in the slurry. The successful and cost-effective design for a wetland restoration project depends on the proper estimation and evaluation of these factors. This will, in return, contribute to the cost-savings, time-savings, and improved outcomes of coastal restoration project implementation.

\section{LABORATORY TESTING}

A series of geotechnical laboratory tests were performed on multiple dredged sediments obtained from different geographic locations along the northern Gulf of Mexico coast. The characteristics of four samples (2013-2 through 2013-5) are presented in this paper. All laboratory tests were conducted in general accordance with applicable American Society for Testing and Materials (ASTM) standard procedures, Environmental Protection Agency (EPA) methods, as well as procedures developed by the US Army Corps of Engineers (USACE).

Classification tests The following geotechnical testing were performed on all sediment samples obtained from the field: (a) natural moisture content (ASTM D2216), (b) Atterberg limits (liquid limit and plastic limit) (ASTM D4318), (c) specific gravity (ASTM D854), (d) organic content (ASTM D2974), and (e) grain size distribution (sieve analysis and hydrometer analysis) (ASTM D422). The site water was characterized by determination of (a) $\mathrm{pH}$, and (b) salinity.

Column settling test To evaluate and estimate the geological and subsidence characteristics of the dredged slurry due to its own weight, as well as the long-term settlement of the marsh creation area foundation soil, a column settling test (CST) was conducted on the dredged materials (USACE EM 1110-2-5027). This test was run for 15 days in a controlled laboratory environment and the sedimentation characteristics of the dredged slurry were monitored on a regular basis. A homogenous slurry was prepared using dredged sediments obtained from the field. The initial solids concentration as well as salinity of the slurry were varied between the tests. The test is run in a 7-foot tall Plexiglas column. The solids-water interface height from the bottom of the column is measured at regular time intervals during the duration of the test. Figure 2 shows pictures from an actual column settling test, 6 hours and 4 days after start of the test for sample 2013-5. 
(a)

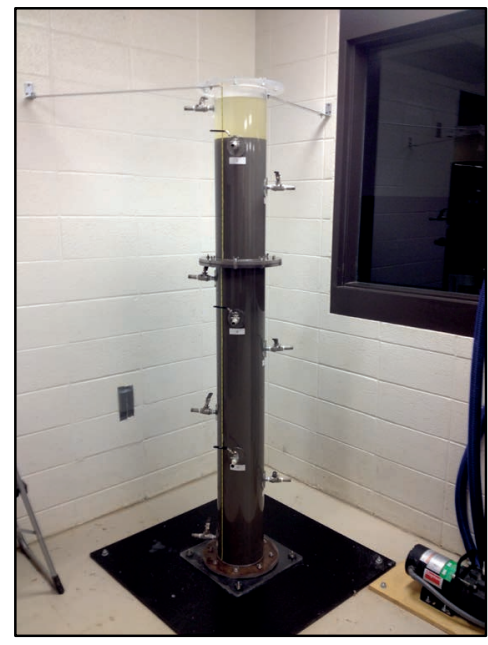

(b)

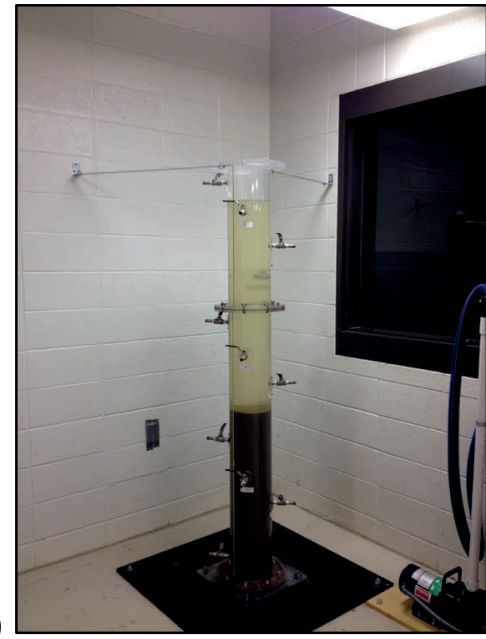

Fig. 2 Column settling test in progress (a) end of 6 hours, (b) end of 4 days for test 2013-5.

Additionally, at regular time intervals, suspended solids samples were obtained through the ports. These samples were used to determine the Total suspended Solids (TSS) in the slurry above the solids-liquid interface line. The collected samples were also used to determine the turbidity values.

Re-suspension test A particle entrainment simulator apparatus, designed by Dr Wilbert Lick, was used to evaluate re-suspension characteristics of the four dredged slurries mentioned previously (Tsai and Lick, 1986). Shear stress levels were controlled through the use of grid oscillation frequency to simulate bed shear stress levels occurring in the field due to water current and wave actions. Prior to the start of each test, the slurry samples were allowed to settle inside the chamber for different time periods (consolidation time). During the test, samples were collected from the suspension zone using a syringe at regular time intervals. These samples were used to determine total suspended solids (TSS) and turbidity values. Figure 3 shows the re-suspension simulator apparatus and the calibration curve developed by Tsai and Lick (1986) and used in the re-suspension analyses.

(a)
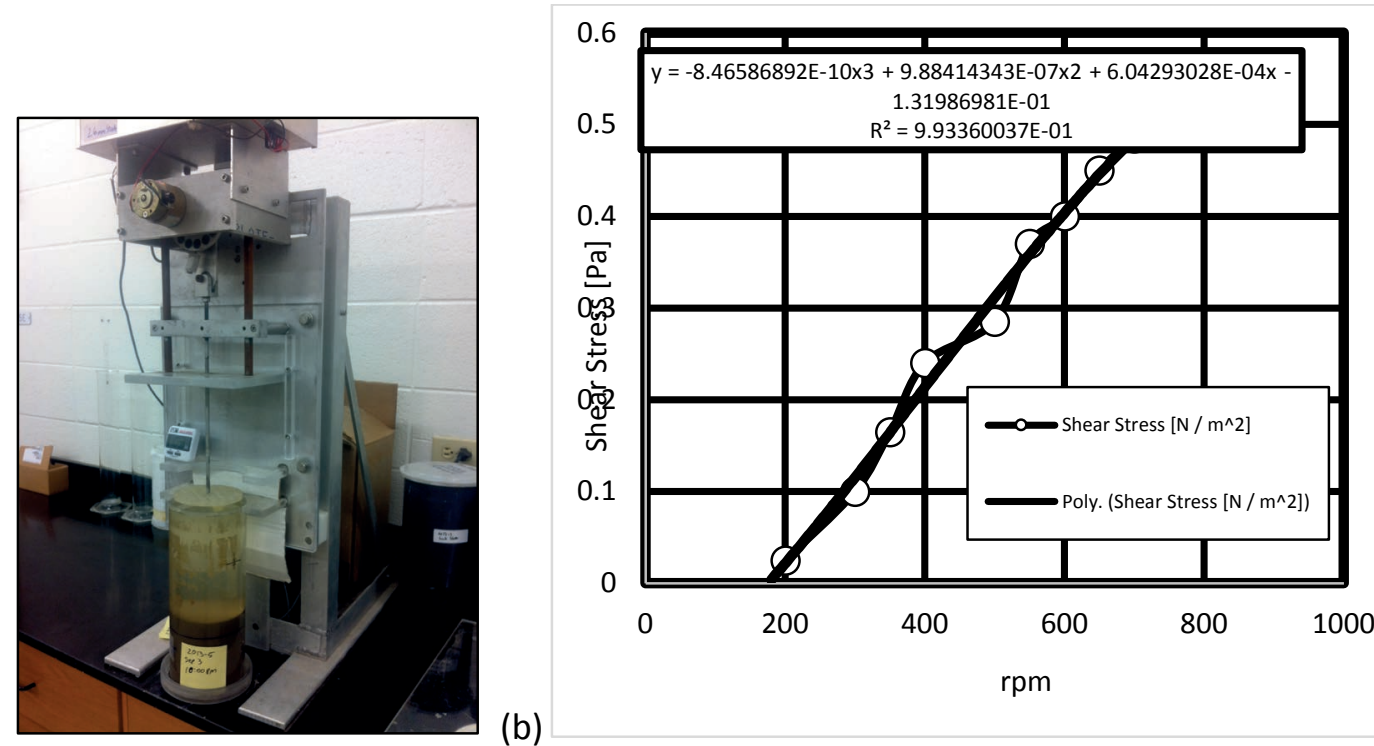

(b)

Fig. 3 Re-suspension apparatus: (a) test in progress, (b) calibration curve. 


\section{MATHEMATICAL MODELLING}

A mathematical model was developed to evaluate long-term performance measures of coastal restoration projects. Different components of the mathematical model are described below:

Distribution silt and clay particles in a coastal environment The distribution of silt and clay particles in a coastal environment is determined by the transporting currents and the net result of re-suspension and depositional fluxes, i.e. a source term defined by:

$$
S_{r}=E_{\text {res }}-V_{d}
$$

where, $E_{\text {res }}$ is the sediment re-suspension flux (mass per unit area per unit time, e.g. g/ $/ \mathrm{m}^{2} / \mathrm{year}$ ) for silt and clay; $V_{d}=$ depositional velocity (McCorquodale et al., 2009).

Re-suspension of silt and clay particles The 2012 Coastal Master Plan (CPRA 2012) used the model from ECOMSED (HydroQual 2002) for the simulation of the re-suspension of cohesive sediments. The Master Plan model for re-suspension had the form:

$$
E_{\text {res }}=\frac{a_{c}}{T_{\text {res }} T_{\text {con }}{ }^{m}}\left(\frac{\tau_{\text {bed }}}{\tau_{c r}}-1\right)^{n}
$$

where $E_{\text {res }}=$ sediment re-suspension flux (mass per unit area per unit time) for silt and clay; $a_{c}$ is a function of the bed properties; $T_{\text {res }}=$ response time of the bed (typically 1 hour); $T_{c o n}=$ the time of consolidation; $m$ and $n$ are constants; $\tau_{b e d}=$ bed shear stress and $\tau_{c r}=$ the critical shear stress for resuspension. The bed shear stress is a function of the shear induced by waves and currents. The values $a_{c}, T_{r e s}, T_{c o n}, m, n$ and $\tau_{c r}$ are set to the default values in ECOMSED and then adjusted by calibration. This approach could be greatly improved by using actual site-specific sediment properties, especially, the critical shear stress for re-suspension and the response of the erosion flux to consolidation time.

Deposition of silt and clay particles in a coastal environment The cohesive sediment deposition rate (e.g. $\mathrm{m} / \mathrm{s}$ ) is a function of the particle grain size distribution and the degree of flocculation. Silt particles are large enough to settle without flocculation; however, colloidal clay particles can remain in suspension for days unless they are flocculated. The discrete silt and particulate clay settling velocities can be computed by Stoke Law:

$$
w_{S}=\frac{g D_{50}^{2}}{18 v}\left(\frac{\rho_{S}}{\rho_{w}}-1\right)
$$

where $D_{50}=$ median diameter of particle $(\mathrm{m}) ; \rho_{s}=$ particle density $\left(\mathrm{kg} / \mathrm{m}^{3}\right) ; \rho_{w}=$ density of the water; $g=$ acceleration due to gravity $\left(\mathrm{m} / \mathrm{s}^{2}\right)$; and $v=$ kinematic viscosity $\left(\mathrm{m}^{2} / \mathrm{s}\right)$.

The flocculation of clay particles depends on the water chemistry, e.g. the concentration of calcium and magnesium ions as well as the shear stress and turbulence intensity. The Delft3d model (Deltares, 2013) simulates flocculation as a function of salinity in which the effective settling velocity varies from the particulate values to the flocculent settling velocity as the salinity varies from near zero to about $5 \mathrm{ppt}$. Typically the flocculent settling velocity is of the order of $1 \mathrm{~mm} / \mathrm{s}$ while the colloidal clay settles at about $10 \mathrm{um} / \mathrm{s}$ (McAnally et al., 2007). Tests on site specific sediments are required to determine the flocculent settling velocity. The effective settling velocity can be expressed as a depositional velocity, $v_{d}$, by the Krone (1962) equation:

$$
v_{d}=w_{s}\left(1-\frac{\tau_{b e d}}{\tau_{d}}\right)
$$

where $w_{s}=$ settling velocity $(\mathrm{m} / \mathrm{s}) ; \tau_{\text {bed }}=$ bed shear stress $(\mathrm{Pa}) ; \tau_{d}=$ critical velocity for initiation of deposition $(\mathrm{Pa})$.

\section{RESULTS AND DISCUSSION}

Geotechnical properties of the four slurry samples are presented in Table 1. The rate and nature (degree of curvature and slope) of sedimentation of the dredged slurry was monitored for 15 days during each experiment. The settling curves, presented in Fig. 4, represent two distinct settlement phases, namely zone settling and compression settling (USACE EM 1110-2-5027). The slope of 
Table 1 Geotechnical properties of dredged slurry samples.

\begin{tabular}{lllllllllll}
\hline $\begin{array}{l}\text { Sample } \\
\text { ID }\end{array}$ & Source & $\begin{array}{l}\text { Liquid } \\
\text { limit } \\
(\%)\end{array}$ & $\begin{array}{l}\text { Plasticity } \\
\text { index (\%) }\end{array}$ & $\begin{array}{l}\text { Organic } \\
\text { content } \\
(\%)\end{array}$ & $\begin{array}{l}\text { Specific } \\
\text { gravity }\end{array}$ & pH & $\begin{array}{l}\% \\
\text { coarse }\end{array}$ & $\begin{array}{l}\% \\
\text { fines }\end{array}$ & $\begin{array}{l}\text { Salinity } \\
(\mathrm{ppt})\end{array}$ & $\begin{array}{l}\text { Initial solids } \\
\text { concentration } \\
(\mathrm{g} / \mathrm{L})\end{array}$ \\
\hline $2013-2$ & Galveston, TX & 67 & 39 & 2.3 & 2.64 & 4.66 & 9.8 & 90.2 & 4.66 & 179.63 \\
$2013-3$ & Galveston, TX & 67 & 39 & 2.3 & 2.64 & - & 9.8 & 90.2 & 31 & 199.31 \\
$2013-4$ & Cameron, LA & 79 & 50 & 3.8 & 2.48 & 7.54 & 2.2 & 97.8 & 0.402 & 51.29 \\
$2013-5$ & Cameron, LA & 79 & 50 & 3.8 & 2.48 & 7.72 & 2.2 & 97.8 & 0.62 & 98.41 \\
\hline
\end{tabular}

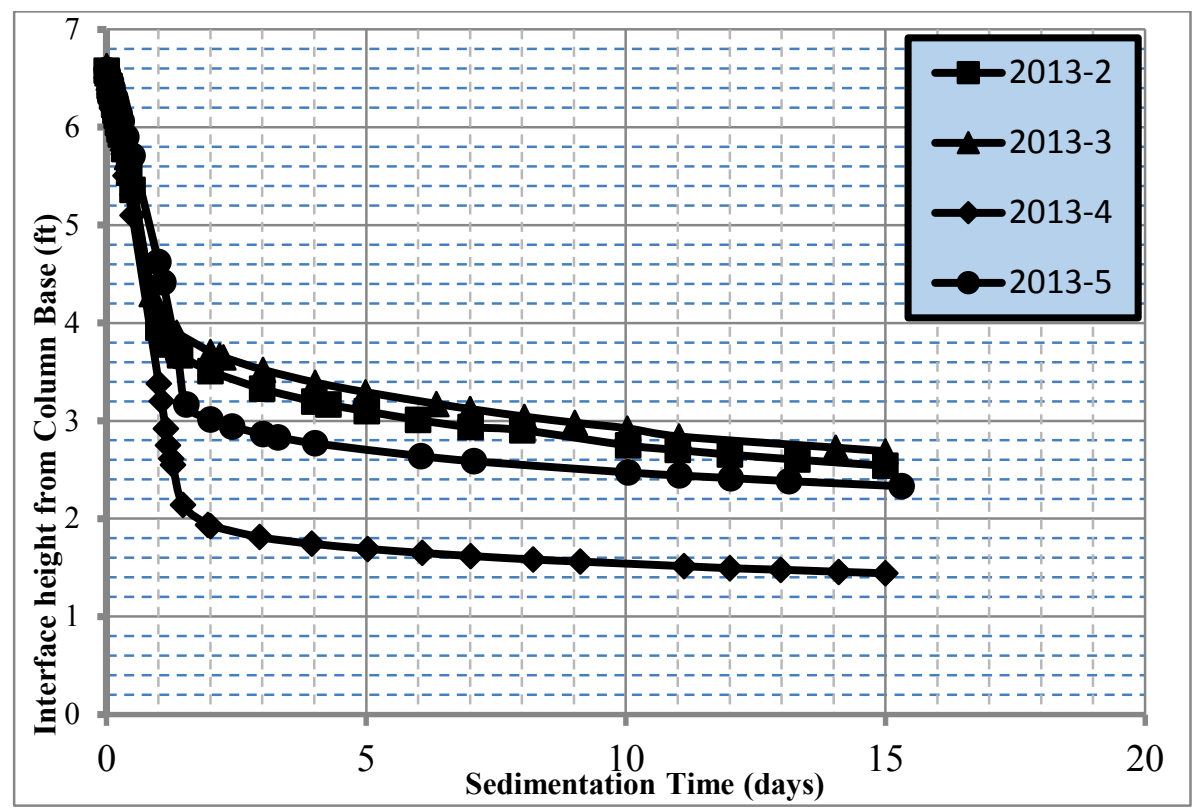

Fig. 4 Settling curves for samples 2013-2, 2013-3, 2013-4, and 2013-5.

the settling curve depends on the grain size distribution, salinity of the slurry, as well as on the initial solids particle concentration in the slurry. As can be seen from the graph, a higher initial solids concentration generally corresponds to lower sedimentation rates. The rate of settling does not appear to have been not greatly affected by change in slurry salinity; however, data are limited.

Using the frequency of oscillation of the disk and corresponding TSS values, the critical bed shear stress $\left(\tau_{c}\right)$ was estimated from each re-suspension test. Because each sample was run after different consolidation times, a graph was generated (Fig. 5) and a relationship derived between $\tau_{c}$ and consolidation time in days $(t)$ :

$$
\tau_{c}=0.02+0.0133 t_{\text {days }}
$$

\section{APPLICATION OF THE LABORATORY RESULTS IN A MATHEMATICAL MODEL}

A mathematical model based on the source term in equation (1) and the critical shear stress in Fig. 5 (equation (5)) was applied to the southeast quadrant of Lake Pontchartrain. The model assumed a 6 day inter-storm period and used the critical shear stress from the regression equation (5) for re-suspension and deposition for silt and clay. The Young and Verhagen (1996) wave model was used to estimate the bed shear stress. The simulated water column concentration of suspended solids is shown in Fig. 6 for a $10 \mathrm{~m} / \mathrm{s}$ wind with a duration of 4 hours; a tidal current of $10 \mathrm{~cm} / \mathrm{s}$ was included. The total concentration of $90 \mathrm{mg} / \mathrm{L}$ is consistent with measurements by Haralampides (2000) at the pier offshore of Pontchartrain Beach. 


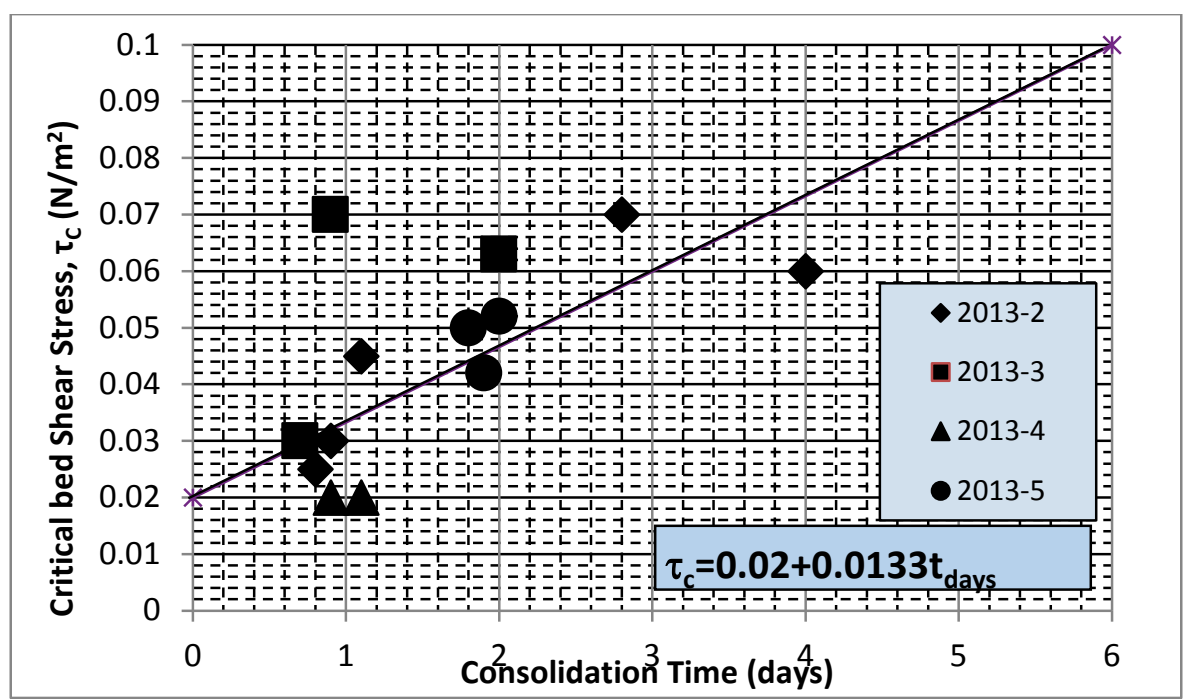

Fig. 5 Variation of critical bed shear stress with consolidation time.

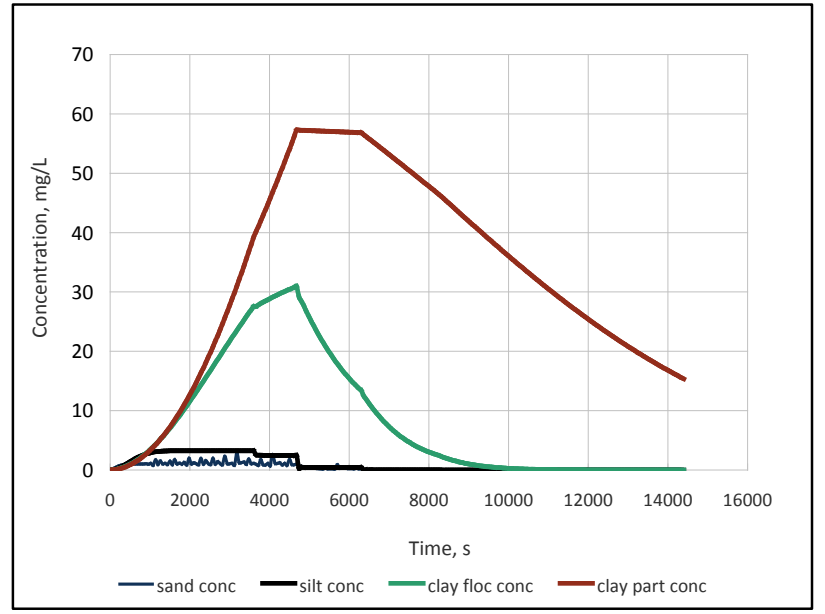

Fig. 6 Modelled re-suspension and deposition of coastal sediments in a brackish lake.

\section{SUMMARY}

Sea level rise, the increasing number and intensity of coastal storms, and other natural and human hazards are putting more people and property at risk along Louisiana's coast. As of 2012 an estimated 1880 square miles (486 917 ha) of Louisiana coastal land has been lost. One of the major goals towards re-establishing a healthy hydro-geomorphic ecosystem is to rebuild wetlands with river/canal/lake sediment diversion or sediment conveyance projects that optimally manage and allocate sediments. This paper presents the results of sedimentation and re-suspension characteristics of four dredged samples obtained from different geographic locations. In general, a higher initial particle concentration resulted in a steeper slope for the settling zone portion of the settling curve. Based on limited tests performed and presented in this paper, the rate of settling does not appear to have been not greatly affected by change in slurry salinity. Additional tests are being performed to evaluate the effects of slurry salinity on settling characteristics of sediments. A simple relationship was derived between critical bed shear stress and consolidation time. The critical bed shear stress value from this relationship was used in a mathematical model to predict long-term performance measures for actual coastal restoration projects in the gulf coast area. Based on the analyses performed, the critical shear stress values obtained from this study matched closely with published values in the literature (Deltares, 2013). 


\section{REFERENCES}

American Society for Testing and Materials (ASTM) International (2013) Annual book of ASTM Standards. ASTMS.

CPRA (Coastal Protection and Restoration Authority) (2012) Louisiana's Comprehensive Master Plan for a Sustainable Coast. 190p. http://www.coastalmasterplan.la.gov

Deltares. (2013) Ch. 11: Sediment transport and morphology. In: Delft3D-FLOW - Simulation of multi-dimensional hydrodynamic flows and transport phenomena, including sediments - User Manual - Hydro-Morphodynamics, version 3.15.30059.

Ghose Hajra, M. and Mattson, G. (2014) Characterization of coastal dredged sediments used in land restoration projects. Proceedings of 2014 Geo-Congress: Geo-Characterization and Modeling for Sustainability, February, 2014, Atlanta, GA.

Haralampides, K. (2000). A study of the hydrodynamics and salinity regimes of the Lake Pontchartrain system. PhD dissertation, Engineering and Applied Science in the Department of Civil and Environmental Engineering, University of New Orleans, New Orleans, Lousiana, USA.

HydroQual, Inc. (2002) A primer for ECOMSED. User's Manual, ver. 1.3. HydroQual, Inc., Mahwah, New Jersey, pp. 188.

Krone, R.B. (1962) Flume studies of the transport of sediment in estuarial shoaling processes, Final Report. Hydr. Engrg Lab. Univ. of California, Berkeley, CA.

Lick, W., Lick, J. and Ziegler, C.K. (1994) The resuspension and transport of fine-grained sediments in Lake Erie. Journal of Great Lakes Research, 20(4), 599-612.

McAnally, W. H., et al. (2007). Management of fluid mud in estuaries, bays, and lakes. i: present state of understanding on character and behavior. Journal of Hydraulic Engineering, 133(1), 9-22.

McCorquodale, et al. (2009) Salinity, nutrient and sediment dynamics in the Pontchartrain estuary. Journal of Coastal Research, Special Volume 54(1).

Stark, T., Choi, H., and Schroeder, P. (2005) Settlement of dredged and contaminated material placement areas. I: Theory and use of primary consolidation, secondary compression, and dessication of dredged fill. ASCE Journal of Waterway, Port, Coastal, and Ocean Engineering, March/April 2005, 43-51

Stark, T., Choi, H., and Schroeder, P. (2005) Settlement of dredged and contaminated material placement areas. II: Primary consolidation, secondary compression, and dessication of dredged fill input parameters. ASCE Journal of Waterway, Port, Coastal, and Ocean Engineering, March/April 2005, 52-61.

Tsai, C.H. and Lick, W. (1986) A portable device for measuring sediment resuspension. Journal of Great Lakes Research 12(4), 314-321.

US Army Corps of Engineers (1987) Confined disposal of dredged material. Engineer Manual 1110-2-5027, Washington, DC.

Young, I.R. and Verhagen, L.A. (1996a) The growth of fetch limited waves in water of finite depth. Part 1. Total energy and peak frequency. Coastal Engineering 29, 47-78. 